\title{
Different Gate Insulators for Organic Field Effect Transistors
}

\author{
O. Boughias $^{1,2, *}$, M.S. Belkaid ${ }^{1}$,T. Trigaud ${ }^{2}$, R.Zirmi ${ }^{1}$ \\ ${ }^{1}$ Laboratory of Advanced Technology, Department of Electrical Engineering, Electronics, University of Mouloud Mammeri, Algeria \\ ${ }^{2}$ X-LIM UMR 7252 laboratory, University of Limoges/ CNR, France
}

Copyright (C) 2015 by authors, all rights reserved. Authors agree that this article remains permanently open access under the terms of the Creative Commons Attribution License 4.0 International License

\begin{abstract}
The aim of this paper is to study the electrical properties of field effect transistors structures with two different insulators polymers, i.e, poly4, vinylphenol (PVP) and silicon oxide $\left(\mathrm{SiO}_{2}\right)$. In these studies, the organic active layer is always the same it is constituted of pentacene. PVP is an organic material with low $\mathrm{k}$ deposited by spin coating. Significant differences in terms of mobility and leakage current are observed with the two dielectrics. Mobility is almost 10 times higher with $\mathrm{SiO}_{2}$ than with PVP. It is the same with the current leakage that are 1000 times smaller with $\mathrm{SiO}_{2}$.
\end{abstract}

Keywords Organic Field Effect Transistor, Pentacene, Silicon Oxide, Poly (4, Vinylphenol)

\section{Introduction}

The need of new devices more reliable and more powerful pushes development of the microelectronics. Among the different ways of this development, the use of organic materials takes an important place in the actual research technology. The organic electronic presents several advantages versus the classical electronic, among these advantages, the low cost of manufacturing process and the flexibility of its manufacturing support. The new technology does not seek to complete with silicon based electronics. However it can be an alternative for some applications. The aim is to improve the performance of electronic components. We have elaborated two series of organics transistors field effect. In the first one, the poly 4, vinylphenol (PVP) represents the gate insulator. In the second, the silicon oxide $\left(\mathrm{SiO}_{2}\right)$ is used as insulator gate. Electrical properties will be compared between the two series.

The insulator must have: high resistivity to prevent the leakage current between the gate metal and the semiconductor channel, and high dielectric constant to have enough capacitance for channel current flow ${ }^{4}$. There are organic and inorganic dielectric materials which fulfil this role. The functioning voltages observed with silicon oxide used as gate insulator is very high ${ }^{5}$. For this, we are interested to the organic insulators as polymethymetacrylte (PMMA) and ploy(4, vinylphenol) (PVP). These organics insulators should combine low functioning voltage and high stability. With PMMA like gate insulator we have high functioning voltage and highest stability ${ }^{6}$.The PVP is transparent insulator polymer in thin layer, with decomposition temperature neighbouring $330^{\circ} \mathrm{C}$. It is soluble in TFH (Tetra Hydro Furan), in the dioxide and in fast alcohols (methanol, isopropanol, ethanol).The pentacene has greater holes mobility than polymers. This molecule allows the formation of polycrystalline thin films on smooth surface substrate ${ }^{7}$ and gives exceptional characteristics for thin film transistors ${ }^{8}$.

\section{Structures Device and Fabrication of Field Effect Transistor}

Field effect transistors with a composite layer based on insulator polymer, i.e., poly (4, vinylphenol) and silicon oxide were realized. The structure of organic field effect transistor is the classical invested staged configuration called top-contact, were the drain and source electrodes are deposited at the last step of the process on the pentacene.

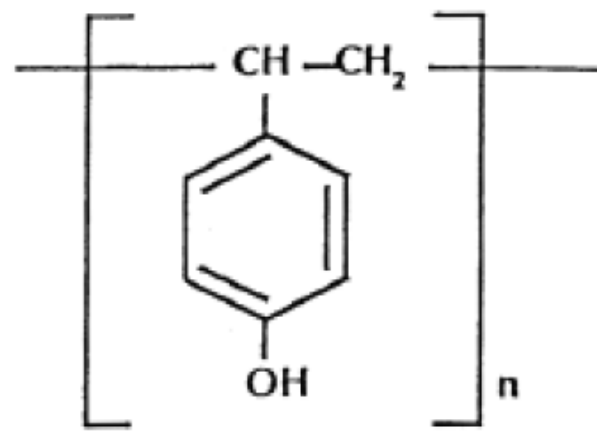

Figure 1. Polymer molecule of $\mathrm{PVP}^{6}$. 
The structure of the studied polymer molecule is shown in Fig. 1. In the first series, the study was carried out from a polymer insulator often used for organic transistors: PVP (poly 4 vinylphenol) ${ }^{4,7}$, where the relative dielectric permittivity is $\sim 3,6$. The insulator polymer PVP used in the present study were purchased in the Sigma-Aldrich and used with additional treatment. PVP was dissolved in isopropanol, the obtained solutions were then mixed, stirred and annealed at temperature of $50^{\circ} \mathrm{C}$ for $30 \mathrm{~min}$. The proportion of the solution was $1 \mathrm{~g}$ of PVP for $5 \mathrm{ml}$ of isopropanol, it is deposited by spin coater layer of the solution of polymer and then dried at $120^{\circ} \mathrm{C}$ for $1 \mathrm{~h} 30 \mathrm{~min}$. The layer thickness was estimated using a Bruker DEKTAK XT as $\sim 1 \mu \mathrm{m}$. The metal

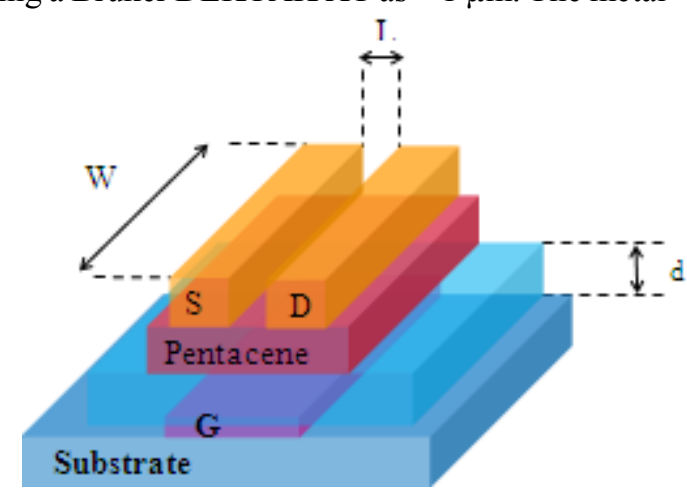

gate is Indium Tin Oxide (ITO), with resistivity of $\sim 10^{-4}$ $\Omega \mathrm{cm}$, etched with a heated hydrochloric acid, and it's layer thickness as $\sim 150 \mathrm{~nm}$. The active layer thickness of pentacene as $\sim 50 \mathrm{~nm}$ deposited using vacuum evaporator, and gold electrode source-drain deposited with the same technical. The layer thickness of electrode was $\sim 50 \mathrm{~nm}$, and the electrode width is $\sim 4 \mathrm{~mm}$.

In the second series, the active layer pentacene is applied on silicon $\left(\mathrm{Si}^{++}\right.$with a $\mathrm{SiO}_{2}$ layer $\left.\sim 20 \mathrm{~nm}\right)$ substrates with thermally deposited $\mathrm{Au}$ electrodes. The silicon substrates were purchased in the Sigma-Aldrich. Figures $2 \mathrm{a}$ and $2 \mathrm{~b}$ shows the structures top contact of field effect transistor with organic and inorganic polymers insulator.

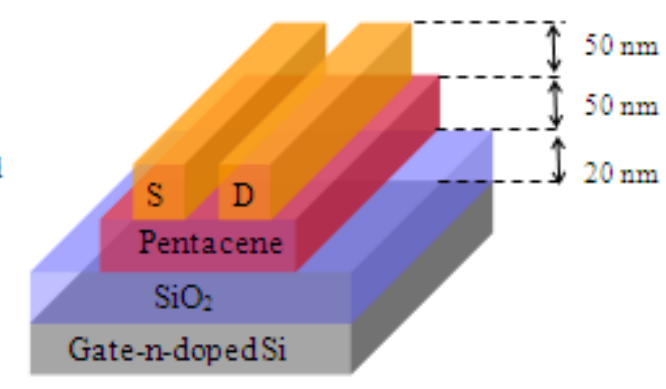

Figure 2. Structure of the top contact field effect transistor studied, (a) with PVP gate insulator and (b) silicon oxide as gate insulator.

Direct current- voltage characteristics of field effect transistor structures based on PVP and silicon oxide were measured in dark, in atmospheric vacuum at $300 \mathrm{~K}$, in a voltage range from -40 to $+40 \mathrm{~V}$, using an automated setup for the measuring $I-V$ characteristics, based on a Keithley-4200 SMU.
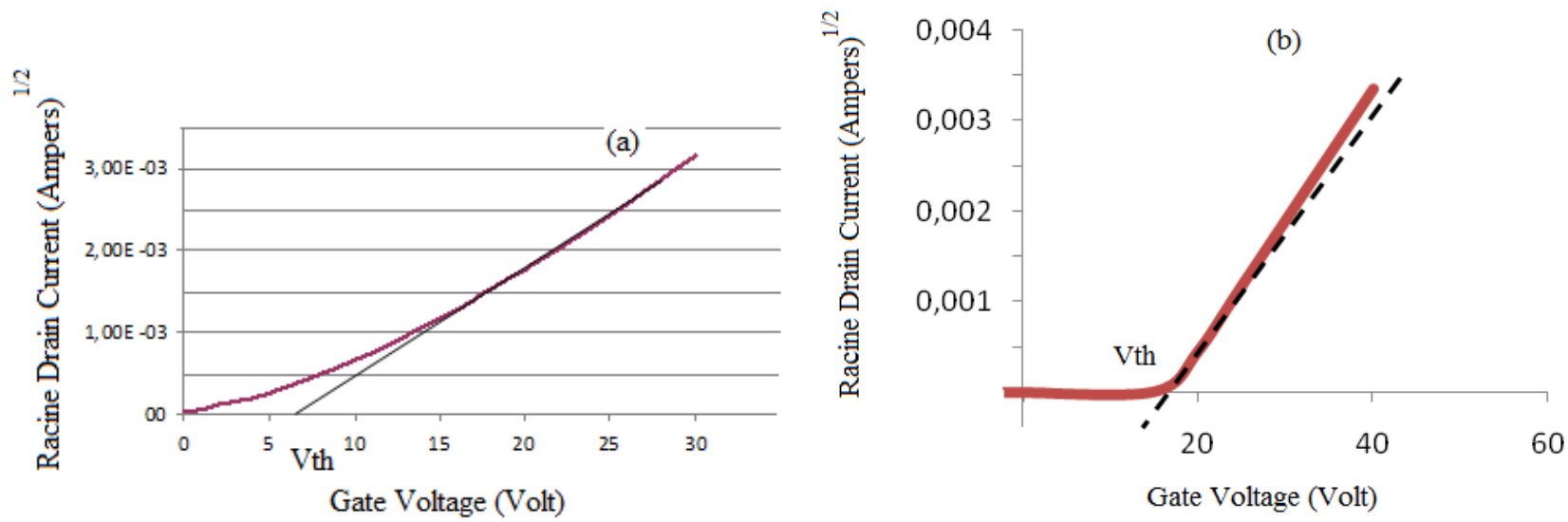

Figure 3. Transient characteristics of field effect transistor with, (a) silicon ( $\mathrm{Si}$ with a $\mathrm{SiO}_{2}$ layer $\sim 20 \mathrm{~nm}$ ), channel length $\sim 100 \mu \mathrm{m}$ at $\mathrm{V}_{\mathrm{DS}}=-40 \mathrm{~V}$ and (b) PVP insulator layer $\sim 1 \mu \mathrm{m}$, channel length $\sim 100 \mu \mathrm{m}$ at $\mathrm{V}_{\mathrm{DS}}=-15 \mathrm{~V}$. 


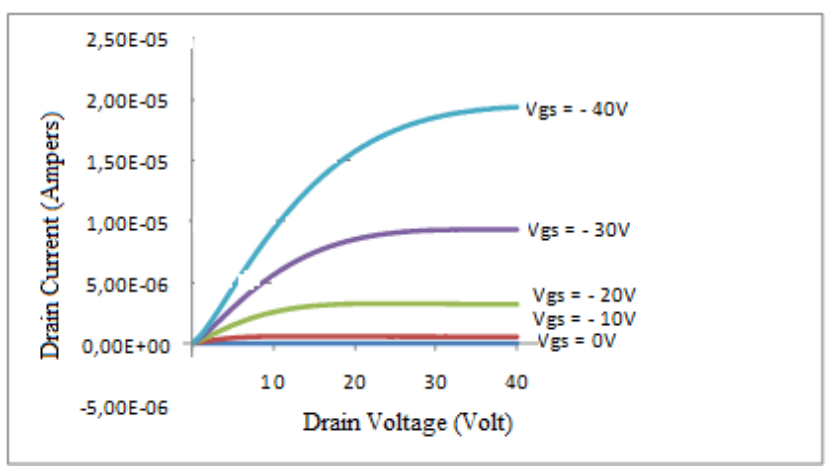

Figure 4. Current-voltage characteristics of field effect transistor with silicon ( $\mathrm{Si}$ with $\mathrm{SiO}_{2}$ layer $\sim 20 \mathrm{~nm}$ ), channel length $\sim 100 \mu \mathrm{m}$ at $\mathrm{V}_{\mathrm{DS}}=-40$ $\mathrm{V}$.

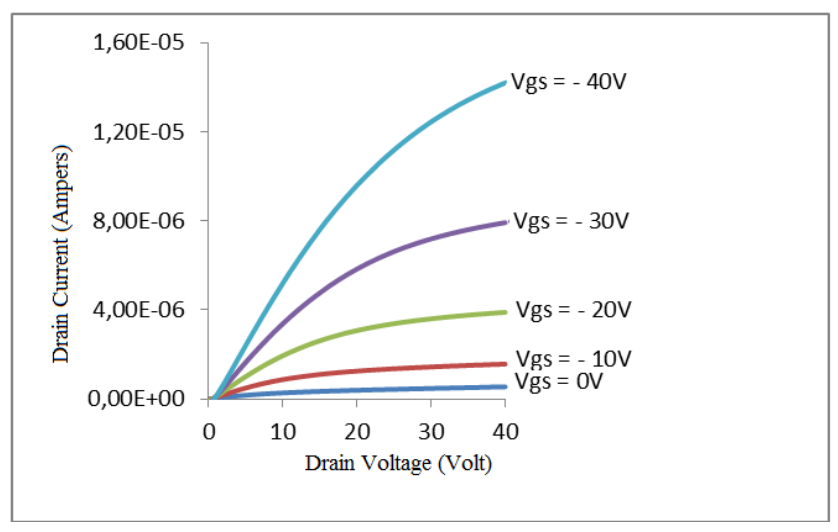

Figure 5. Current-voltage characteristics of field effect transistor with insulator layer $\mathrm{PVP} \sim 50 \mathrm{~nm}$, channel length $\sim 100 \mu \mathrm{m}$ at $\mathrm{V}_{\mathrm{DS}}=-40 \mathrm{~V}$.

\section{Results and Discussion}

Figures 4 and 5 show the $I-V$ characteristics of the field effect transistor with insulator organic layer PVP for the first series, and insulator silicon oxide inorganic layer for the second series. We observe an improvement of drain current, with the silicon oxide insulator compared with the use of insulator polymer PVP. The measured $I-V$ characteristics are typical of the unipolar hole field effect transistor operating under current saturation conditions at voltages slightly exceeding a certain threshold value $\mathrm{V}_{\text {th }}$. The charge carrier mobility $\mu_{\mathrm{FET}}$ of the active layer was estimated from the I-V characteristic of the field effect transistor under saturation and weak-field conditions, respectively, from the relations ${ }^{9,10}$.

$$
\begin{gathered}
I_{D S}=(W / 2 L) \mu_{F E T} C i\left(V_{G}-V_{t h}\right)^{2} \\
\mathrm{I}_{\mathrm{DS}}=(\mathrm{W} / \mathrm{L}) \mu_{\mathrm{FET}} \mathrm{Ci}\left(\mathrm{V}_{\mathrm{G}}-\mathrm{V}_{\mathrm{th}}\right) \mathrm{V}_{\mathrm{DS}}
\end{gathered}
$$

Where in our case $\mathrm{W}=4 \mathrm{~mm}$ is the channel width, $\mathrm{L}=100 \mu \mathrm{m}$ is the channel length, $\mathrm{Ci}$ is the capacitance per square area of the polymer insulator: for $\mathrm{SiO}_{2}$ and for a thickness of $\sim 20 \mathrm{~nm}, \mathrm{Ci} \sim 1,15.10^{-9} \mathrm{pF} / \mathrm{cm}^{2}$ and for PVP with a thickness of $\sim 1 \mu \mathrm{m}, \mathrm{Ci} \sim 2,3 \mathrm{nF} / \mathrm{cm}^{2}$. $\mathrm{V}_{\mathrm{G}}$ is the gate voltage, and $\mathrm{V}_{\text {th }}$ is threshold voltage corresponding to the accumulation mode beginning. For the field effect transistor based on the silicon oxide, the threshold voltage $\mathrm{V}_{\text {th }} \sim-7 \mathrm{~V}$ was estimated from the dependence of $\mathrm{I}_{\mathrm{DS}}{ }^{0.5} \mathrm{on}$ $\mathrm{V}_{\mathrm{GS}}$ at $\mathrm{V}_{\mathrm{DS}}=-40 \mathrm{~V}$ (Fig. 3a) and the field effect transistor based on PVP, the threshold voltage $\mathrm{V}_{\text {th }} \sim-18 \mathrm{~V}$ was estimated on $V_{G S}$ at $V_{D S}=-15 V$ (Fig. 3b). For a better comparison we decided to represent the same curve on the current-voltage characteristics based on the silicon oxide and PVP insulators polymers for fixed gate voltages. The Figure 6 shows the $I-V$ characteristic of the field effect transistor at gate voltage $\mathrm{V}_{\mathrm{GS}}=-30 \mathrm{~V}$. The field effect mobility are $0.04 \mathrm{~cm}^{2} \cdot \mathrm{V}^{-1} \cdot \mathrm{s}^{-1}$ with PVP as insulator and $0.3 \mathrm{~cm}^{2} \cdot \mathrm{V}^{-1} \cdot \mathrm{s}^{-1}$ with silicon oxide. This difference is attributed to the high roughness of the PVP layer. One can also think that there are impurities at the interface PVP pentacene as leakage currents are higher with PVP the Ion/Ioff ratio was shown to be around $10^{6}$ with $\mathrm{SiO}_{2}$ and $10^{3}$ with PVP.

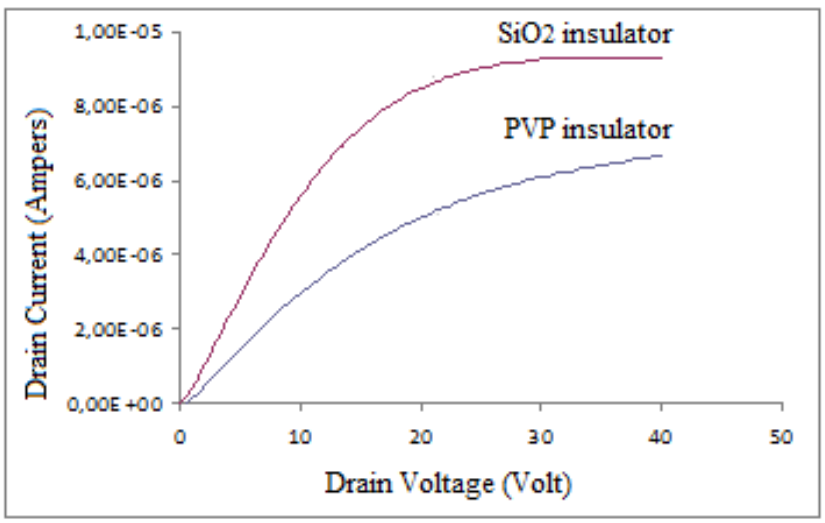

Figure 6. Current-voltage characteristics of the field effect transistor with insulator layer based on solution 5 of $1 \mathrm{~g} / \mathrm{ml} \mathrm{PVP:} \mathrm{isopropanol,} \mathrm{active}$ layer was pantacene, and gold electrode source-drain compared to field effect transistor with silicon oxide, $\mathrm{Vgs}=-30 \mathrm{~V}$.

\section{Conclusions}

The manufacture of completely organic transistor requires the use of polymer dielectric. These dielectric are often inefficient because it generates low mobility and significant leakage currents. These two features are related to the quality of the interfaces and to defects or impurities in the polymer. We have shown here that the performance were at least 10 times lower in the case of using organic insulator compared to usual used inorganic insulator as $\mathrm{SiO}_{2}$.

\section{REFERENCES}

[1] T. A.Skotheim and J. R. Reynolds, Handbook of Conducting Polymers, $3^{\text {rd }}$ ed. (CRC Press, New York, 2007), ISBN 978-1-4200-4360-0. 
[2] C. November, D. Guerin, K. Lmimouni, C. Gamrat, and D. Vuillaume, Appl. Phys. Lett. 92, 103314 (2008).

[3] M. F. Mabrook, Y. Yun, C. Pearson, D. A. Zeze, and M. C. Petty, Appl. Phys. Lett. 94, 173302 (2009).

[4] S. Allard, M. Foster, B. Souhare, H. Thiem, and U. Scherf, organic semiconductors for solution-processable field effect transistors (OFETs), organic Electronics reviews, 2008.

[5] A. Attias, Engineering technical, conjugated polymers and electrical conduction polymers, E 1 862-p 8.

[6] I. El Houti El Jazairi, Printed transparent organic transistors based on pentacene, Doctorat these, , Limoges university, (2009).

[7] H. Klauk, M. Halik, U. Zschieschang, F. Eder, G. Schmid, C.
Dehm, Appl. Phys. Lett,82, 4175, (2003).

[8] R. Schroeder, L.A. Majeswski, M. Grell, improving organic transistor performance with Schottky contacts, Appl. Phys. Lett., 84, 1004, (2004).

[9] C.D. Dimitrakopoulos and P.R.L. Malenfant, organic thin film transistor for large area electronics. Advanced Materials, 14(2) : 99-117, (2002).

[10] J. Horowitz, Adv. Master. (Weinheim) 10, 365 (1998).

[11] A. N. Aleshim, F. S. Fedichkin, and P. E. Gusakov, memory effects in field effect transistor structures based on composite films of polyepoxypropylcarbazole with gold nanoparticles, physics of the solid state, vol. 53, $\mathrm{N}^{\circ}$. 11, pp. 2370-2374, (2011). 